\title{
Parental Conditional Regard, Subjective Well-Being and Self-Esteem: The Mediating Role of Perfectionism
}

\author{
Ece Mendi, Jale Eldeleklioğlu \\ Counseling Psychology Department, Faculty of Education, University of Uludag, Bursa, Turkey \\ Email: ecemendi@yahoo.com, eldelek@uludag.edu.tr
}

How to cite this paper: Mendi, E., \& Eldeleklioğlu, J. (2016). Parental Conditional Regard, Subjective Well-Being and SelfEsteem: The Mediating Role of Perfectionism. Psychology, 7, 1276-1295.

http://dx.doi.org/10.4236/psych.2016.710130

Received: May 5, 2016

Accepted: September 3, 2016

Published: September 6, 2016

Copyright $\odot 2016$ by authors and Scientific Research Publishing Inc. This work is licensed under the Creative Commons Attribution International License (CC BY 4.0).

http://creativecommons.org/licenses/by/4.0/

\begin{abstract}
The present study investigated the relationship between parental conditional regard, perfectionism, subjective well-being and self-esteem, and the role of perfectionism as a mediator in the relationship between parental conditional regard and both subjective well-being and self-esteem. Using a convenience sampling, 500 Turkish university students $(\mathrm{M}$ age $=20.83$ years old, $\mathrm{SD}$ age $=2.05)$ completed questionnaires. The results showed positive links between parental conditional regard and perfectionism, negative links between parental conditional regard and both subjective well-being and self-esteem and negative links between perfectionism and both subjective wellbeing and self-esteem. While perfectionism was a partial mediator between parental conditional regard and self-esteem, perfectionism was not a mediator between parental conditional regard and subjective well-being.
\end{abstract}

\section{Keywords}

Parental Conditional Regard, Perfectionism, Subjective Well-Being, Self-Esteem, Adolescence

\section{Introduction}

Parental conditional regard is a form of parental attitude, in which the love, affection, and appreciation shown towards children are dependent on whether they fulfill certain expected behaviors (Assor, Roth, \& Deci, 2004). The concept of unconditional positive regard was first described by Rogers (1959), who has suggested that all individuals need to receive unconditional positive regard from persons who occupy an important place in their lives, especially their parents (Rogers, 1959). Although certain researchers claim 
that parental conditional regard reinforces in children the behaviors considered as positive by their parents (Gewirtz \& Pelaez-Nogueras, 1991), other researchers have described that parental conditional regard can adversely affect the psychology of children (Assor et al., 2004; Assor \& Roth, 2007; Assor \& Tal, 2012). Parental conditional regard consists of four dimensions, which are prosocial behavior, sports performance, academic success, and emotion control; it is possible for parents exhibiting conditional regard in one of these dimensions to not display conditional regard in another dimension (Assor \& Roth, 2007).

The definition and dynamics of parental conditional regard can be clarified by relating it to concepts used in self-determination theory. The self-determination theory describes that the motivation of individuals is either autonomous (i.e. intrinsic) or controlled (i.e. extrinsic) (Ryan \& Deci, 2000). Autonomous motivation is defined as the form of motivation in which the behavior of the individual is determined more by personal beliefs and values than external factors with the individual taking his/her own decisions and having a feeling of choice. In controlled motivation, on the other hand, the individual's behavior is shaped by external pressures with the individual feeling coerced to display certain behaviors (Budak, 2000). It has been suggested that parental conditional regard is a control-oriented attitude, and that it might lead to negative behavioral outcomes such as controlled motivation, controlled behavior and internalization (Soenens \& Vansteenkiste, 2010).

The negative consequences of parental conditional regard highlighted by previous studies include internalization (Shavit-Miller \& Assor, 2003), introjected regulation (Assor et al., 2005), low subjective well-being, negative feelings towards parents (Assor et al., 2004; Roth et al., 2009), low performance in areas that are conditional for parental love and affection (Assor \& Roth, 2007), low coping skills, fluctuations in the level of self-esteem, short-termed satisfaction, feelings of shame after failure (Assor \& Tal, 2012), low self-esteem, and in engaging in romantic relations (Roth \& Assor, 2003).

\subsection{Subjective Well-Being}

Diener (2000) defined subjective well-being as a form of satisfaction and positive mental health that includes both cognitive and affective components. Three important components of subjective well-being are positive effect, negative effect, and life satisfaction. Positive affect includes positive feelings such as trust, interest, hope, excitement, pride, joy, and appreciation; while negative affect includes subjective stress and dissatisfaction, which are associated with negative feelings such as anger, hate, guilt, and sadness. Life satisfaction is the cognitive component of the subjective well-being, and reflects the individual's own assessment regarding various aspects of his/her life, such as work and marriage. On the other hand, Lyubomirsky and Dickerhoof (2006) described the concept of subjective well-being as an individual self-assessment that is not equivalent to having superior function in all areas, and which is constantly experienced at a subliminal level by the individual. 
Although it is known that peers and friends have an important effect on the subjective well-being of individuals during adolescence, it is also important to take into account the attitude of the parents, since adolescence cannot be considered independently of childhood (Driscoll et al., 2008). Studies on the subjective well-being of adolescents and children have demonstrated that democratic parental attitudes increase the subjective well-being of children (Park, 2004), while children with parents using punishment-based approaches exhibit lower academic performance and more social problems (Fletcher et al., 2008). Such studies have also evaluated the effect of demographic factors (age, gender, socio-economic level, education level, civil status, etc.) and personal characteristics (self-concept, extraversion, internal focus of control, etc.) (Huebner, 1991). There have also been studies which investigate whether the factors affecting subjective well-being are universal or long-lasting and which analyze the extent to which they are dependent on cultural characteristics (Diener \& Suh, 2000). With regard to parental conditioning, it is expected that the reduction or denial of the affection shown by parents when the children fail to achieve expectations will adversely affect subjective well-being.

\subsection{Self-Esteem}

Self-esteem is defined as an individual's general sense of self-worth, as well as the individual's belief that he/she is a valuable person (Rosenberg, 1979). Factors that influence the development of self-esteem include a general feeling of wellness; the ability to demonstrate one's skills; personal achievements; being appreciated and admired within society; being accepted and liked by others; and the acceptance of one's own physical characteristics and traits (Saygın \& Arslan, 2009). Individuals with high self-esteem have higher self-respect; feel more valuable; do not consider themselves as being better or worse than others; are aware of the personal boundaries of others; and expect that they will experience personal development over time. On the other hand, individuals with low self-esteem are dissatisfied overall with themselves; have low self-respect; and generally hold a negative self-image (Mayhew \& Lempers, 1998). Mead (1934) investigated the effect of integration into social groups on the development of self-esteem, and observed that when the persons that an individual considers as important appreciate and value him/her in return, the individual will also value him/herself. According to Rogers (1959), self-esteem depends on the sense of value the individual receives from his/her social environment. For this reason, the healthy development of self-esteem among children is associated with the unconditional acceptance they receive from their environment for who they are. Herz and Gullone (1999) described that the attitude and level of support shown by parents have an influential role in the adaptive or maladaptive behavior demonstrated by children, emphasizing that children seeing strong support and acceptance from their family tend to display higher self-esteem, as well as greater competence in their activities. Oppressive behavior from parents, on the other hand, can cause adolescents to feel incompetent, unsuccessful, and inadequate. 
High self-esteem has been linked with high academic performance, social adaptation, confidence, desire to achieve and optimism; it also known to reinforce the sense of being liked and valued by others (Taşgit, 2012). Individuals with stronger communication skills and greater creativity can assume more active roles in society. Nowadays, it is generally suggested that high self-esteem is closely associated with higher life satisfaction (Bean \& Northrup, 2009). Low self-esteem, on the other hand, is known to result in a higher incidence of emotional and behavioral disorders such as anxiety (Rosenberg, 1962; Kawash, 1982; Bagana et al., 2011), social isolation (Leary, 1990; Zhao et al., 2012; Saricam et al., 2012), low life satisfaction (Zhang \& Leung, 2002; Bozorgpour \& Salimi, 2012; Kong \& You, 2013), suicidality (Franck et al., 2007), aggressiveness (Teng et al., 2015), cyber bullying (Brewer \& Kerslake, 2015), low motivation, susceptibility to anger (Waschull \& Kernis, 1996; Papps \& O’Carroll, 1998), eating disorders (Joiner \& Kashubeck, 1996; Brechan \& Kvalem, 2015), substance dependence (Workman \& Beer, 1989), depression (Sowislo \& Orth, 2013), and criminal tendencies (Trzesniewski et al., 2006).

\subsection{Perfectionism}

Perfectionism mainly originates from individuals' desire to be loved, accepted, and approved, as well as their fear of being rejected (Pamir, 2008). Frost et al. (1990) defined perfectionism as an approach in which individuals set excessively high and unrealistic standards for themselves; assess themselves in an extremely critical manner; and inadvertently follow forms of behavior that are ultimately self-defeating. Previous studies particularly evaluated the effect of parental factors on the development of perfectionism, and suggested that perfectionists are generally individuals raised in environments where love and appreciation were conditional (Frost et al., 1990).

Hamachek (1978) divided perfectionism into two groups as "normal perfectionism" and "neurotic perfectionism." Neurotic perfectionists tend to harbor a constant anxiety about meeting/achieving high standards, while normal perfectionists do not display such anxious behavior. Researchers suggested that neurotic perfectionism generally appears among individuals raised in familial environments where affection and appreciation were conditional (Hamachek, 1978).

Behaviors exhibited by perfectionists include the need to constantly check and verify their own actions; the need to repeatedly correct themselves; constant approval-seeking; excessive planning; difficulty in making decisions; procrastination; avoidance; and attempting to change others. Low self-esteem has an important role in these behaviors exhibited by perfectionist individuals (Atasoy, 2014). Studies indicate that perfectionism has a positive relationship with depression (Hewitt \& Flett, 1991; Bieling et al., 2003; Argus \& Thompson, 2008; Sherry et al., 2014; Cheng et al., 2015), anxiety (Kawamura et al., 2001), personality traits (Hewitt, Flett, \& Turnbull, 1992; Stoeber et al., 2015), and eating disorders (Brouwers \& Wiggum, 1993; Shafran \& Mansell, 2001; Stice, 2002; Jacobi et al., 2004; Bardone-Cone et al., 2007; Egan, Wade, \& Shafran, 2011; Luo et al., 2013). Similarly, unhealthy perfectionism appears to have a negative relationship with self-esteem (Ashby \& Rice, 2002). Perfectionist individuals tend to experience more problems in interpersonal relations, and to display higher levels of 
anxiety (Slaney \& Ashby, 1996). In addition, it has been observed that perfectionism has a positive relationship with pessimism and stress levels, and that perfectionists generally have lower levels of satisfaction with themselves and their lives (Mitchelson \& Burns, 1998).

\subsection{Mediating Role of Perfectionism}

Acceptance, approval, support and feelings of belonging occupy a considerably important place in interpersonal relations (Pamir, 2008). Parental conditional regard refers to the tendency of parents to display affection and appreciation only when children display certain behaviors (Assor et al., 2004). Such an attitude contributes to the development of perfectionism among children due to their need for parental acceptance, and the significance they attribute to their parent's expectations (Pamir, 2008; Frost et al., 1990). Hoping to receive acceptance and approval from their parents, perfectionist children tend to develop a highly critical perspective of themselves, consequently bearing a constant fear of failure, while also feeling an implicit resentment towards their parents. Such an attitude among children is associated with a high negative effect, which is a sub-dimension of subjective well-being; these children are consequently expected to have low subjective well-being. Shim et al. (2013) previously determined that associating success with the appreciation and judgment of others led to negative emotions about one's self. Individuals who feel worthless when faced with failure, and who are unable to come to terms with their mistakes, are expected to have lower self-esteem (Coopersmith, 1981; Rogers, 1951). Assor et al. (2004) determined in their study that children who experience parental conditional regard tend to experience considerable fluctuations in their self-esteem levels. The realization that their parent does not accept them the way they are adversely affects the self-esteem of the child (Assor \& Roth, 2007). As a result, perfectionism is expected to mediate the relationship of parental conditional regard with subjective well-being and self-esteem.

\section{Purpose}

In light of the studies demonstrating the relationship between parental conditional regard, perfectionism, subjective well-being, and self-esteem, it seems possible that parental conditional regard-which has detrimental effects on the psycho-social functioning of individuals-may enhance perfectionism, while also reducing subjective well-being and self-esteem. Aside from this, it seems possible that perfectionism may reduce both the subjective well-being and self-esteem of individuals. The main purpose of this study was to investigate whether perfectionism plays a mediating role in the relationship of parental conditional regard with subjective well-being and self-esteem for Turkish university students. In other words, our aim was to determine how perfectionism relates to parental conditional regard, subjective well-being, and self-esteem. In the mediation model, we first examined whether perfectionism acts as a mediator between parental conditional regard and subjective well-being, and then evaluated whether it acts as a mediator between parental conditional regard and self-esteem. 


\section{Method}

\subsection{Participants}

The study participants included 500 students [335 (67\%) females, 165 (33\%) males] attending the Education Faculty, Engineering Faculty, Economics Faculty, Administrative Sciences Faculty, Science and Letters Faculty, and the Foreign Language School of Uludağ University. The age of the study participants ranged between 18 and 25 years (mean $=20.83, \mathrm{SD}=2.05)$. In this study, $86(17.2 \%)$ of the students were preparatory class students, 168 (33.6\%) were first-year students, 100 (20.0\%) were second-year students, $80(16 \%)$ were third-year students, and 66 (13.2\%) were fourth-year students. Participants were selected using the convenience sampling method.

\subsection{Instruments}

The Parental Conditional Regard Scale, which was developed by Assor et al. (2004) in accordance with the concept of self-determination, assesses the parental conditional regard university students experienced during childhood or adolescence. The scale consists of four dimensions, which are prosocial behavior, sports performance, academic performance and emotion control. The scale has a total of 24 items, and is based on a six-point Likert-type design (1: never; 6: always). Cronbach's Alpha $(\alpha)$ internal consistency coefficient of the scale was 0.87 for the mother, and 0.83 for the father. The scale was adapted to Turkish by Helvac1 (2010), with only the "academic performance" and "emotion control" dimensions being included in the Turkish version. These two dimensions consist of a total of 12 items, with the $\alpha$ coefficient value for parental regard being calculated as higher than 0.76 for both dimensions. The lowest total score that can be obtained with the scale is 12 , while the highest total score is 72 . In both dimensions, a higher score is associated with a higher parental conditional regard. In the present study, the Cronbach's alpha coefficient was determined as 0.91 for the "academic success" dimension, and 0.77 for the "emotion control" dimension.

The Multidimensional Perfectionism Scale was developed by Frost et al. (1990) to assess the level of perfectionism among adolescents. The scale consists of six dimensions, which are personal standards, concerns over mistakes, organization, doubts about actions, parental expectations and parental criticism. The scale is based on a five-point Likert-type design, with each item receiving a score between 1 and 5 (1: strongly disagree; 5 : strongly agree). The scale consists of a total of 35 items. The lowest total score that can be obtained with the scale is 35 , while the highest total score is 175 . A higher score is associated with higher level of perfectionism. The $\alpha$ coefficient value of the original scale is 0.90 . The Turkish adaptation of the scale was prepared by Özbay and Misırl1-Taşdemir (2003), and the reliability coefficient of this adapted version was calculated as $\alpha=0.83$. In the present study, the Cronbach's alpha coefficient was determined as 0.87 .

The Adolescent Subjective Well-Being Scale was developed by Eryllmaz (2009) to assess the subjective well-being of adolescents. The Adolescent Subjective Well-Being Scale consists of 15 items and 4 dimensions, which are satisfaction with parental rela- 
tions, satisfaction with relations with important persons, life satisfaction, and positive emotions. The scale is based on a four-point Likert-type design, with each item receiving a score between 1 and 4 (1: strongly disagree; 4: strongly agree). The lowest total score that can be obtained on the scale is 15 , while the highest total score is 60 . A higher score is associated with a higher level of subjective well-being. The total reliability coefficient ( $\alpha$ ) of the scale is 0.88 . In the present study, the Cronbach's alpha coefficient was determined as 0.90 .

The Rosenberg Self-Esteem Scale was developed by Rosenberg (1965) to assess the self-esteem of adolescents. The scale consists of 63 items and 12 dimensions, which are self-respect, continuity of the notion of self-worth, reliance on others, sensitivity to criticism, depressive emotions, dreaminess, psychosomatic symptoms, feeling threatened in interpersonal relations, ability to join discussions, parental interest, relations with father and psychic isolation. The scale also includes 10 items organized according to the Guttman scale format. The Rosenberg Self-Esteem Scale is based on a four-point Likert-type design, with each item receiving a score between 0 and 3 (0: strongly disagree; 3: strongly agree). The lowest total score that can be obtained on the scale is 0 , while the highest total score is 30. A higher score is associated with a higher self-esteem. The scale was adapted to Turkish by Çuhadaroğlu (1986). The test-retest reliability coefficient of the scale was determined as 0.70 . In this study, we used the 10-item Rosenberg Self-Esteem Scale organized according to the Guttman format, and recalculated the Cronbach's Alpha $(\alpha)$ internal consistency coefficient for the scale. In the present study, the Cronbach's alpha coefficient was determined as 0.87 .

\subsection{Procedure and Data Analysis}

The scales were administered by the researchers to the participating students from Uludağ University. Prior to the study procedures, all students were informed regarding the purpose of the study and the scales. The students were also informed that none of the scales have "right" or "wrong" answers, and that their responses will be kept confidential. The Parental Conditional Regard Scale, the Multidimensional Perfectionism Scale, the Adolescent Subjective Well-Being Scale, and the Rosenberg Self-Esteem Scale were all provided to the students within a single form. Incomplete forms, as well as erroneously completed forms, were excluded from the study. Each study participant completed the scales within approximately 25 minutes.

The Pearson correlation coefficient and hierarchical regression analyses were used to determine the relationships between the study variables. In this study, we followed the recommendations from Baron and Kenny's (1986) in analyzing with hierarchical regression analyses whether perfectionism mediated the relationship of parental conditional regard with subjective well-being and self-esteem. The independent variable is parental conditional regard, the hypothesized mediating variable is perfectionism and the dependent variables are subjective well-being and self-esteem. According to these researchers' recommendations, it is first necessary to identify a significant relationship between the independent variable and the hypothesized mediating variable. Secondly, it 
is also necessary to identify a significant relationship between the hypothesized mediating variable and the dependent variable. Thirdly, it is necessary to determine a significant relationship between the independent variable and the dependent variable. As a final condition, when the mediating variable is included in the regression analysis together with the independent variable, the significance of the regression coefficient indicating the predictive effect of the independent variable on the dependent variable must decrease (or disappear entirely), while the mediating variable still continues to have a significant effect on the dependent variable.

\section{Results}

\subsection{Descriptive Data and Inter-Correlations}

Table 1 shows the means, descriptive statistics, and inter-correlations of the variables that were used. When Table 1 is examined, it possible to see that, the correlational analysis indicated significant relationships between the study variables. A positive relationship was identified between the parental conditional regard and perfectionism $(\mathrm{r}=$ 0.42), while a moderate level negative relationship was identified between the parental conditional regard and subjective well-being $(r=-0.32)$ and between the parental conditional regard and self-esteem $(r=-0.42)$. All of these relationships had a significance level of 0.01 . On the other hand, the relationship between perfectionism and subjective well-being $(r=-0.13)$ and between perfectionism and self-esteem $(r=-0.30)$ were negative. The relationship between self-esteem and subjective well-being was strong and positive $(r=0.52)$.

According to the correlations shown above, an increase in parental conditional regard was associated with an increase in perfectionism, and a decrease in subjective well-being and self-esteem. On the other hand, an increase in perfectionism was associated with a decrease in subjective well-being and self-esteem, while an increase in subjective well-being was associated with a parallel increase in self-esteem.

\subsection{Testing the Mediating Role of Perfectionism in the Relationship between Parental Conditional Regard and Subjective Well-Being}

To test the mediating effects of perfectionism on the relationships between parental conditional regard and subjective well-being, we first determined whether parental

Table 1. Descriptive statistics and inter-correlations of the variables.

\begin{tabular}{lcccccccc}
\hline \multicolumn{1}{c}{ Variable } & 1 & 2 & 3 & 4 & Mean & SD & Skewness & Kurtosis \\
\hline 1) Parental Conditional Regard & - & & & & 18.88 & 9.80 & 1.84 & 3.43 \\
2) Perfectionism & $0.42^{* *}$ & - & & & 102.07 & 17.12 & 0.08 & 0.24 \\
3) Subjective Well-Being & $-0.32^{* *}$ & $-0.13^{* *}$ & - & & 49.3 & 7.45 & -0.91 & 1.36 \\
4) Self-Esteem & $-0.42^{* *}$ & $-0.30^{* *}$ & $0.52^{* *}$ & - & 21.26 & 5.31 & -0.47 & -0.01
\end{tabular}

${ }^{* *} p<0.01$. 
conditional regard and perfectionism were positively related $(\beta=0.42, \mathrm{t}=10.58, p<$ 0.01 ), and then verified whether perfectionism and subjective well-being were negatively related $(\beta=-0.13, \mathrm{t}=-3.1, p<0.01)$. A hierarchical regression analysis was used to test the final steps of the mediation procedure. The results of the hierarchical regression analysis suggested that parental conditional regard was negatively related with subjective well-being. As shown in Table 2, the first stage of the hierarchical regression analysis evaluated only the effect of the parental conditional regard on subjective well-being, and determined that parental conditional regard accounted for $10 \%$ of the subjective well-being $[\mathrm{F}(1,49)=58.58, p=0.00]$. As shown in Table 2, when perfectionism was included in the second stage of the hierarchical regression analysis, it was observed that it did not have a significant predictive effect for subjective well-being ( $\beta=$ $0.00, \mathrm{t}=0.00)\left[\mathrm{R}^{2}=0.10, \Delta \mathrm{R} 2=0.10, \mathrm{~F}(2,49)=29.23, p=0.00\right]$. This result suggested that perfectionism was not the mediator of the relationship between parental conditional regard and subjective well-being. In other words, perfectionism did not have a mediating role between parental conditional regard and subjective well-being.

Figure 1 shows the mediation model between the variables.

\subsection{Testing the Mediating Role of Perfectionism on the Relationship between Parental Conditional Regard and Self-Esteem}

It was determined that parental conditional regard and perfectionism were positively

Table 2. Evaluation of the mediating role of perfectionism on the relationship between parental conditional regard and subjective well-being.

\begin{tabular}{|c|c|c|c|c|c|}
\hline Variable & $\mathrm{B}$ & Standard Error & B & $\mathrm{t}$ & $\mathrm{F}$ \\
\hline \multicolumn{6}{|l|}{ Step 1} \\
\hline Parental Conditional Regard & -0.24 & 0.03 & -0.32 & -7.65 & 58.58 \\
\hline \multicolumn{6}{|l|}{ Step 2} \\
\hline Parental Conditional Regard & -0.24 & 0.03 & -0.32 & -6.91 & \multirow[b]{2}{*}{29.23} \\
\hline Perfectionism & 0.00 & 0.02 & 0.00 & 0.00 & \\
\hline
\end{tabular}

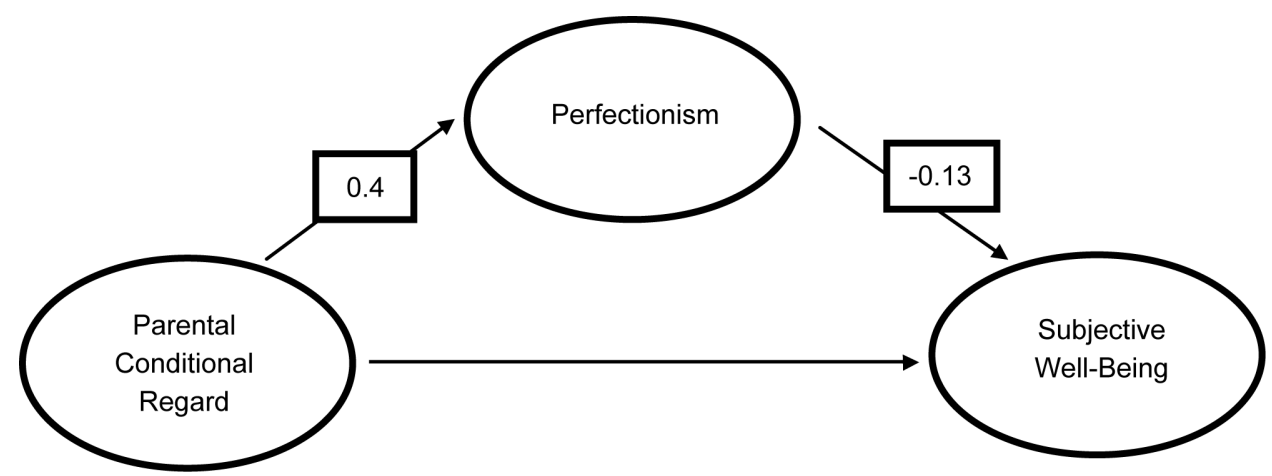

Figure 1. Evaluation of whether perfectionism significantly mediated the association between parental conditional regard and subjective well-being. 
related $(\beta=0.42, \mathrm{t}=10.58, p<0.01)$, while perfectionism and self-esteem were negatively related $(\beta=-0.31, \mathrm{t}=-7.18, p<0.01)$.

A hierarchical regression analysis was used to test the last steps of the mediation procedure. The results of the hierarchical regression analysis indicated that parental conditional regard was negatively related with self-esteem. Baron and Kenny (1986) previously described that such a result demonstrates a partial mediation. As shown in Table 3, the first stage of the hierarchical analysis evaluated only the effect of the parental conditional regard on self-esteem, and determined the parental conditional regard accounted for $18 \%$ of self-esteem $[\mathrm{F}(1,49)=111.14, p=0.00]$. In addition, when parental conditional regard and perfectionism were evaluated together in the regression analysis, the significance of the relationship between parental conditional regard and self-esteem decreased, while the relationship between parental conditional regard and self-esteem remained significant $(\beta=-0.36, \mathrm{t}=-8.16)\left(\mathrm{R}^{2}=0.18, \Delta \mathrm{R} 2=0.18, \mathrm{~F}(2,49)\right.$ $=62.53, p=0.00)$. It can thus be said that perfectionism partially mediated the relationship between parental conditional regard and self-esteem. The relevant results are shown in Table $3(\beta=-0.15, \mathrm{t}=-3.40, p<0.05)$.

By using the SPSS macro process (Preacher, Rucker, \& Hayes, 2007) indirect effect in simple mediation was estimated. This process involves not only normal theoretical approach such as Baron and Kenny's approach (Baron \& Kenny, 1986) but also bootstrapping approach to obtain bias-corrected confidence intervals. Bootstrapping includes drawing repeated data samples with replacement to gain multiple estimates of the indirect effect (Preacher \& Hayes, 2008). In bootstrapping, significant results are found with $95 \%$ confidence interval that does not contain zero (Preacher \& Hayes, 2008). In this study, the indirect effect was significant because the bootstrapped $95 \%$ confidence interval did not contain zero $(-0.05,-0.01)$.

Figure 2 shows the mediation model between the variables. As indicated by Figure 2 , when only parental conditional regard was regressed, the beta weight on self-esteem was -0.42 . The beta weight then decreased from -0.42 to -0.36 when perfectionism was added into the equation.

\section{Discussion}

The aim of this study was to investigate the relationships between parental conditional

Table 3. Evaluation of the mediating role of perfectionism on the relationship between parental conditional regard and self-esteem.

\begin{tabular}{cccccc}
\hline Variable & B & Standard Error & B & t & F \\
\hline Step 1 & & & & & \\
Parental Conditional Regard & -0.23 & 0.02 & -0.42 & -10.54 & 111.14 \\
Step 2 & & & & \\
Parental Conditional Regard & -0.19 & 0.02 & -0.36 & -8.16 & 62.53 \\
Perfectionism & -0.04 & 0.01 & -0.15 & -3.40 & \\
\hline
\end{tabular}




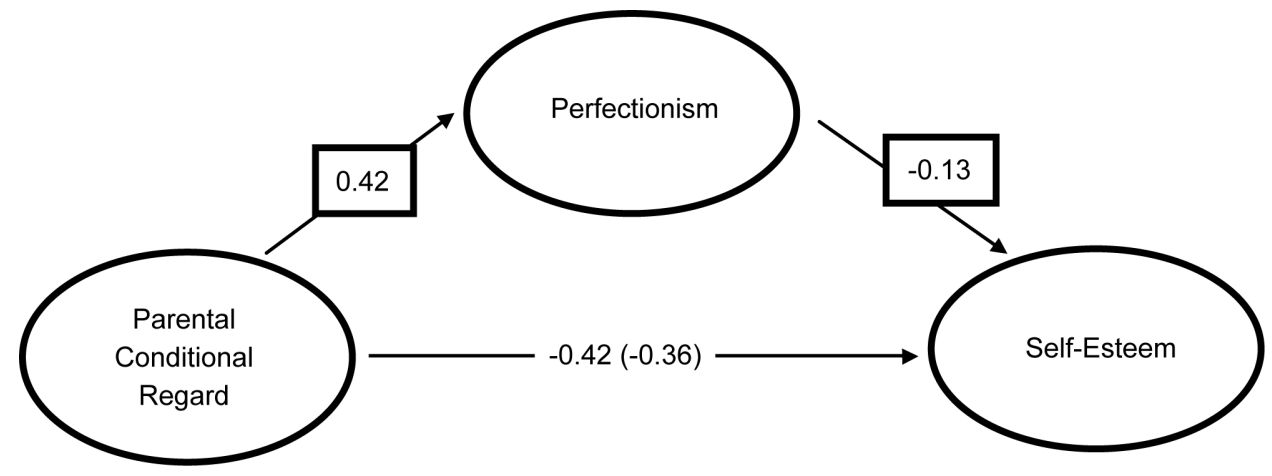

Figure 2. Evaluation of whether perfectionism significantly mediated the association between parental conditional regard and self-esteem.

regard, perfectionism, subjective well-being, and self-esteem, and to evaluate the mediating role of perfectionism between parental conditional regard and subjective well-being for Turkish university students. To this end, we first used correlation analyses to examine the relationships between parental conditional regard, perfectionism, subjective well-being, and self-esteem. We then employed multiple regression analysis to analyze the mediating role of perfectionism on the relationship between parental conditional regard and subjective well-being. The results of the study demonstrated that the parental conditional regard had a positive relationship with perfectionism, and negative relationship with subjective well-being and self-esteem. In addition to this, perfectionism was determined to be negatively related with subjective well-being and self-esteem. Furthermore, it was determined that perfectionism mediated the relationship between parental conditional regard and self-esteem, but that it lacked a similar mediating role between parental conditional regard and subjective well-being. These results were quite significant for a number of reasons: The study results not only contributed to increasing the currently available knowledge regarding parental conditional regard, but also demonstrated the mediating role played by perfectionism-a point that was not observed or addressed in numerous previous studies investigating the negative effects of parental conditional regard.

First of all, the positive relationship observed in this study between parental conditional regard and perfectionism indicated the importance of parental factors in the development of perfectionism-a relationship that has been described in other studies as well (Frost et al., 1990; Hamachek, 1978; Hewitt \& Flett, 1991). Previous studies clearly illustrate that, parents with high expectations who are never satisfied with the success of their children, and who display appreciation towards their children to the extent their expectations are met, contribute to the development of unhealthy perfectionism (Hamachek, 1978; Blatt et al., 1995; McCranie \& Bass, 1984).

Secondly, the negative relationship observed in this study between conditional parental regard and subjective well-being indicated the negative effect of conditional parental regard on subjective well-being. In this respect, the results of the present study were in agreement with the findings of previous studies (Assor et al., 2004; Driscol et 
al., 2008; Shim et al., 2013). For example, Driscol et al. (2008) reported that when parents increased the support they showed to their children, the children felt more appreciated and accepted, and hence exhibited greater self-confidence and happiness. Similarly, Shim et al. (2013) determined that the tendency of viewing the appreciation and judgement of others as a criterion of success/achievement negatively affected the emotions of children. Furthermore, causing children to feel under constant pressure, and preventing them from becoming emotionally independent, contributed to the negative relationship observed between parental conditional regard and subjective well-being (Ryan \& Deci, 2000). The negative relationship between parental conditional regard and self-esteem observed in the present study was parallel with the findings of Assor et al. (2004) study, which illustrated that children experiencing parental conditional were aware that their level of worth and appreciation depended on exhibiting certain behaviors. This, in turn, led to anxiety and fluctuations in their level of self-esteem, which were due to the alternating episodes of brief satisfaction experienced by the children following success, and the shame and sense of worthlessness they experienced following failure (Assor \& Roth, 2007). There are other studies suggesting a negative relationship between parental conditional regard and self-esteem (Coopersmith, 1967; Bachman, 1970; Kernis et al., 2000). For example, Coopersmith's (1967) study reported that children with higher self-esteem generally had families who exhibit warmer attitudes and a higher level of acceptance.

Thirdly, the results of the present study were parallel with the findings of Stoeber and Rambow (2007), illustrating a negative relationship between perfectionism and subjective well-being. Stoeber and Rambow's study demonstrated that negative reactions shown towards adolescents at the slightest mistake they committed or problem they faced, as well as the pressure exerted by parents expecting them to be perfect, adversely affected their motivation and subjective well-being. In addition to these findings, certain studies suggest that both healthy and unhealthy perfectionism can lead to negative effects in individuals such as increased anxiety, stress, and depression (Bieling et al., 2004; Lynd-Stevenson \& Hearne, 1999). However, a number of previous studies also claim that perfectionism among adolescents leads to higher motivation, success, and subjective well-being-although these studies fail to describe whether this increased motivation is due to a desire for success or the fear of failure. One such study is the one performed by Stoeber and Otto (2006), which claims that perfectionism should not be viewed as an exclusively unhealthy behavior, and that healthy perfectionists who are not worried about mistakes or concerned about the negative opinions of others tend to demonstrate good performance. The said study appears to be in contradiction with the findings of our study, which showed that perfectionism has a negative relationship with subjective well-being. This seeming contradiction might have stemmed from the different characteristics of the study participants, as well as the different aspects of perfectionism that were considered within the scope of the two studies. A negative relationship between perfectionism and self-respect was similarly observed in previous studies (Flett et al., 1991; Rice et al., 1998; Gotwals et al., 2012; Ashby et al., 2002). For example, 
Flett et al. (1991) determined that, in a manner similar to parental conditional regard, unrealistic expectations imposed on individuals by others within the frame of socially prescribed perfectionism also led to a higher incidence of depression and lower self-esteem.

Fourthly, the results of our study indicated that perfectionism did not play a mediating role in the relationship between parental conditional regard and subjective wellbeing. Similar findings were also described in studies suggesting a positive relationship between perfection and subjective well-being. For example, Stoeber and Otto (2006) suggested that perfectionism can have positive effects such as increasing success and motivation. Stoeber and Otto also considered self-oriented perfectionism as a positive form of perfectionism, and described that it would not have a negative effect on subjective well-being. Bieling et al. (2004) similarly determined that perfectionism resulted in both positive and negative emotions. Adler (1977) described that perfectionism is healthy as long as the individual is also able to concurrently develop his/her skills, and that it is actually necessary for self-actualization (Greenspon, 2000). Thus, although parental conditional regard leads to negative emotions among children, it appears that this effect is not mediated through perfectionism, since perfectionism can result in a range of both negative and positive emotions.

Finally, it was observed that an increase in parental conditional regard was associated with a decrease in self-esteem, and that this effect was partially mediated by perfectionism. This observation is in agreement with the findings of previous studies, which describe that children subject to parental conditional regard tend to experience feelings of worthless after failure, and that their self-esteem varies considerably due to the low level of acceptance they see from their parents. As a result, these two factors partly lead these individuals to become perfectionists (Assor et al., 2004; Flett et al., 1991). Considering the importance of family support in the development of self-esteem, it is inevitable that parental conditional regard, accompanied by very low acceptance and tolerance by the parents, will lead to low self-esteem among children. Within the frame of perfectionism, low self-esteem results from the self-imposed notion that the individual should not make any mistakes under any circumstances; this notion, in turn, stems from the conditional appreciation and affection which parents display towards their children. The mediating role of perfectionism is associated with the overly self-critical attitude children acquire as a result of the low self-esteem caused by the parental conditional regard.

\section{Limitations}

The present study had a number of limitations. First of all, the study was performed with students from a single university, which limits the generalizability of the study results. To increase the generalizability of the study results, the relationship of parental conditional regard with other variables can be evaluated using different sampling methods. Another limitation of the study was the fact that study data were obtained using self-assessment forms. In future studies, parents can also be evaluated together with their children, and by using the applicable assessment tools and observational methods. 
In addition, alternative approaches could be considered and utilized for evaluating parental conditional regard. Furthermore, parents whose attitude towards their children causes low self-esteem can be evaluated with the scope of longitudinal studies, and data from different stages of the individuals' lives can be evaluated. Finally, the parental conditional regard of adolescents can be evaluated based on their childhood experiences, allowing other important factors from this period to be included into the relevant analyses.

\section{Conclusion}

In conclusion, we believe that despite its limitations, this study will contribute significantly to the existing literature. This study investigated the mediating role of perfectionism on the relationship of parental conditional regard with subjective well-being and self-esteem. Therefore, the study determined not only the relationships of these variables with one another, but also the effect of perfectionism on all these relationships. In addition to this, by demonstrating the negative effect of parental conditional regard on the subjective well-being and self-esteem level of adolescents, the study also showed the importance of parental regard and attitude in the psycho-social development of both children and adolescents. The study clearly illustrates that when parents show appreciation and affection towards children exclusively when they display particular behaviors, they not only fail to play a positively reinforcing role in their children's development, but also cause the children to feel valuable only under certain specific circumstances (and hence devoid of value or worth in all other circumstances), thereby hampering the proper development of their children's individualism and self-esteem. In light of all these findings, we can recommend that parents are informed about such negative effects through effective parental attitude seminars organized by psychological counselors, and that the parents are taught about the psychological harms of conditional parental regard on children psychology.

\section{Funding}

This study reports on the master thesis project and is funded by Uludag University Scientific Research Project entitled "The relationship between parental conditional regard, perfectionism, subjective well-being and self-esteem" which has a project number called KUAP (E) 2014/27.

\section{References}

Adler, S. (1977). Maslow's Need Hierarchy and the Adjustment of Immigrants. The International Migration Review, 11, 444-451. http://dx.doi.org/10.2307/2545398

Argus, G., \& Thompson, M. (2008). Perceived Social Problem Solving, Perfectionism, and Mindful Awareness in Clinical Depression: An Exploratory Study. Cognitive Therapy and Research, 32, 745-757. http://dx.doi.org/10.1007/s10608-006-9102-1

Ashby, J. S., \& Rice, K. G. (2002). Perfectionism, Dysfunctional Attitudes, and Self-Esteem: A Structural Equations Analysis. Journal of Counseling and Development, 80, 197-203. 
http://dx.doi.org/10.1002/j.1556-6678.2002.tb00183.x

Assor, A., \& Roth, G. (2007). The Harmful Effects of Parental Conditional Regard. Scientific Annals of the Psychological Society of Northern Greece, 5, 17-34.

Assor, A., \& Tal, K. (2012). When Parents' Affection Depends on Child's Achievement: Parental Conditional Positive Regard, Self-Aggrandizement, Shame and Coping in Adolescents. Journal of Adolescence, 35, 249-260. http://dx.doi.org/10.1016/j.adolescence.2011.10.004

Assor, A., Cohen-Malayev, M., Kaplan, A., \& Friedman, D. (2005). Choosing to Stay Religious in a Modern World: Socialization and Exploration Processes Leading to an Integrated Internalization of Religion among Israeli Jewish Youth. Advances in Motivation and Achievement, 14, 105-150. http://dx.doi.org/10.1016/S0749-7423(05)14005-9

Assor, A., Roth, G., \& Deci, E. L. (2004). The Emotional Costs of Perceived Parents' Conditional Regard: A Self-Determination Theory Analysis. Journal of Personality, 72, 47-89. http://dx.doi.org/10.1111/j.0022-3506.2004.00256.x

Atasoy, P. Ç. (2014). Perfectionism. http://www.burem.boun.edu.tr/?q=node/55

Bachman, J. G. (1970). Youth in Transition (Vol. 2). Ann Arbor, MI: Institute for Social Research, University of Michigan.

Bagana, E., Raciu, A., \& Lupu, L. (2011). Self-Esteem, Optimism and Exams' Anxiety among High School Students. Procedia-Social and Behavioral Sciences, 30, 1331-1338.

http://dx.doi.org/10.1016/j.sbspro.2011.10.258

Bardone-Cone, A. M., Wonderlich, S. A., Frost, R. O., Bulik, C. M., Mitchell, J. E., \& Uppala, S. et al. (2007). Perfectionism and Eating Disorders: Current Status and Future Directions. Clinical Psychology Review, 27, 3384-3405. http://dx.doi.org/10.1016/j.cpr.2006.12.005

Baron, R. M., \& Kenny, D. A. (1986). The Moderator-Mediator Variable Distinction in Social Psychological Research: Conceptual, Strategic, and Statistical Considerations. Journal of Personality and Social Psychology, 51, 1173-1182.

http://www.public.asu.edu/ davidpm/classes/psy536/Baron.pdf

http://dx.doi.org/10.1037/0022-3514.51.6.1173

Bean, R. A., \& Northrup, J. C. (2009). Parental Psychological Control, Psychological Autonomy, and Acceptance as Predictors of Self-Esteem in Latino Adolescents. Journal of Family Issues, 30, 1486-1504. http://dx.doi.org/10.1177/0192513X09339149

Bieling, P. J., Israeli, A. L., \& Anthony, M. M. (2004). Is Perfectionism Good, Bad, or Both? Examining Models of the Perfectionism Construct. Personality and Individual Differences, 36, 1373-1385. http://dx.doi.org/10.1016/S0191-8869(03)00235-6

Bieling, P. J., Israeli, A., Smith, J., \& Antony, M. M. (2003). Making the Grade: The Behavioural Consequences of Perfectionism in the Classroom. Personality and Individual Differences, 35, 163-178. http://dx.doi.org/10.1016/S0191-8869(02)00173-3

Blatt, S. J., Quinlan, D. M., Pilkonis, P. A., \& Shea, M. T. (1995). Impact of Perfectionism and Need for Approval on the Brief Treatment of Depression: The National Institute of Mental Health Treatment of Depression Collaborative Research Program Revisited. Journal of Consulting and Clinical Psychology, 63, 125-132. http://dx.doi.org/10.1037/0022-006X.63.1.125 http://www.researchgate.net/profile/Paul_Pilkonis/publication/15302209_Impact_of_perfectio nism_and_need_for_approval_on_the_brief_treatment_of_depression_the_National_Institute _of_Mental_Health_Treatment_of_Depression_Collaborative_Research_Program_revisited/li nks/5453a4790cf26d5090a54b09.pdf

Bozorgpour, F., \& Salimi, A. (2012). State Self-Esteem, Loneliness and Life Satisfaction. Procedia-Social and Behavioral Sciences, 69, 2004-2008.

http://dx.doi.org/10.1016/j.sbspro.2012.12.157

Brechan, I., \& Kvalem, I. L. (2015). Relationship between Body Dissatisfaction and Disordered 
Eating: Mediating Role of Self-Esteem and Depression. Eating Behaviors, 17, 49-58. http://dx.doi.org/10.1016/j.eatbeh.2014.12.008

Brewer, G., \& Kerslake, J. (2015). Cyberbullying, Self-Esteem, Empathy and Loneliness. Computers in Human Behavior, 48, 255-260. http://dx.doi.org/10.1016/j.chb.2015.01.073

Brouwers, M., \& Wiggum, C. D. (1993). Bulimia and Perfectionism: Developing the Courage to Be Imperfect. Journal of Mental Health Counseling, 15, 141-159.

Budak, S. (2000). Psychology Glossary. Ankara: Bilim ve Sanat Yayınları.

Cheng, P., Dolsen, M., Girz, L., Rudowski, M., Chang, E., \& Deldin, P. (2015). Understanding Perfectionism and Depression in an Adult Clinical Population: Is Outcome Expectancy Relevant to Psychological Functioning? Personality and Individual Differences, 75, 64-67. http://dx.doi.org/10.1016/j.paid.2014.10.053

Coopersmith, S. (1967). The Antecedents of Self-Esteem. San Francisco, CA: W. H. Freeman.

Coopersmith, S. (1981). SEI Self-Esteem Inventories Manual. Redwood City, CA: Mind Garden.

Diener, E. (2000). Subjective Well-Being: The Science of Happiness and a Proposal for a National Index. American Psychologist, 55, 34-43. http://dx.doi.org/10.1037/0003-066X.55.1.34

Diener, E., \& Suh, E. M. (Eds.) (2000). Culture and Subjective Well-Being. Cambridge, MA: MIT Press.

Driscoll, A. K., Russell, S. T., \& Crockett, L. J. (2008). Parenting Styles and Youth Well-Being across Immigrant Generations. Journal of Family Issues, 29, 185-209. http://dx.doi.org/10.1177/0192513X07307843

Egan, S. J., Wade, T. D., \& Shafran, R. (2011). Perfectionism as a Transdiagnostic Process: A Clinical Review. Clinical Psychology Review, 31, 203-212.

http://dx.doi.org/10.1016/j.cpr.2010.04.009

Eryılmaz, A. (2009). Developing Adolescent Subjective Well Being Scale. Journal of Turkish Educational Sciences, 7, 975-989.

Fletcher, A. C., Walls, J. K., Cook, E. C., Madison, K. J., \& Bridges, T. H. (2008). Parenting Style as a Moderator of Associations between Maternal Disciplinary Strategies and Child Well-Being. Journal of Family Issues, 29, 1724-1744. http://dx.doi.org/10.1177/0192513X08322933

Flett, G. L., Hewitt, P. L., Blankstein, K. R., \& Koledin, S. (1991). Dimensions of Perfectionism and Irrational Thinking. Journal of Rational-Emotive and Cognitive-Behavior Therapy, 9, 185201. http://dx.doi.org/10.1007/BF01061229 http://www.researchgate.net/profile/Paul_Hewitt/publication/225945274_Dimensions_of_Perf ectionism_and_Anxiety_Sensitivity/links/0f3175355e1d38e058000000.pdf

Franck, E., De Raedt, R., Dereu, M., \& Van Den Abbeele, D. (2007). Implicit and Explicit Self-Esteem in Currently Depressed Individuals with and without Suicidal Ideation. Journal of Behavior Therapy and Experimental Psychiatry, 38, 75-85. http://dx.doi.org/10.1016/j.jbtep.2006.05.003

Frost, R., Marten, R., Lahart, C., \& Rosenblate, R. (1990). The Dimensions of Perfectionism. Cognitive Therapy and Research, 14, 449-468. http://dx.doi.org/10.1007/BF01172967

Gewirtz, J. L., \& Pelaez-Nogueras, M. (1991). Proximal Mechanisms Underlying the Acquisition of Moral Behavior Patterns. In W. M. Kurtines, \& J. L. Gewirtz (Eds.), Handbook of Moral Behavior and Development: Vol. 1, Theory (pp. 153-182). Hillsdale, NJ: Erlbaum.

Gotwals, J. K., Stoeber, J., Dunn, J. G. H., \& Stoll, O. (2012). Are Perfectionistic Strivings in Sport Adaptive? A Systematic Review of Confirmatory, Contradictory, and Mixed Evidence. Canadian Psychology, 53, 263-279. http://dx.doi.org/10.1037/a0030288 
Greenspon, T. S. (2000). "Healthy Perfectionism" Is an Oxymoron! Reflections on the Psychology of Perfectionism and the Sociology of Science. Journal of Secondary Gifted Education, 11, 197-208. http://www.positivedisintegration.com/Greenspan2000.pdf

Hamachek, D. E. (1978). Psychodynamics of Normal and Neurotic Perfectionism. Psychology (Savannah, Ga.), 15, 27-33.

Helvac1, E. (2010). The Impact of Perceived Parental Control on Internalization and Ego-Depletion. Unpublished Master Thesis, Ankara: ODTÜ.

Herz, L., \& Gullone, E. (1999). The Relationship between Self-Esteem and Parenting Style: A Cross-Cultural Comparison of Australian and Vietnamese Australian Adolescents. Journal of Cross-Cultural Psychology, 30, 742-761. http://dx.doi.org/10.1177/0022022199030006005

Hewitt, P. L., \& Flett, G. L. (1991). Perfectionism in the Self and Social Context: Conceptualization, Assessment and Association with Psychopathology. Journal of Personality and Social Psychology, 60, 456-467. http://dx.doi.org/10.1037/0022-3514.60.3.456

Hewitt, P. L., Flett, G. L., \& Turnbull, W. (1992). Perfectionism and Multiphasic Personality Inventory (MMPI) Indices of Personality Disorder. Journal of Psychopathology and Behavioral Assessment, 14, 323-335.

http://www.researchgate.net/profile/Paul_Hewitt/publication/225881740_Perfectionism_and_ multiphasic_personality_inventory_\%28MMPI\%29_indices_of_personality_disorder/links/ 0f3175355e1d3ed381000000.pdf http://dx.doi.org/10.1007/BF00960777

Huebner, E. S. (1991). Correlates of Life Satisfaction in Children. School Psychology Quarterly, 6, 103-111. http://dx.doi.org/10.1037/h0088805

Jacobi, C., Hayward, C., de Zwaan, M., Kraemer, H. C., \& Agras, S. (2004). Coming to Terms with Risk Factors for Eating Disorders: Application of Risk Terminology and Suggestions for a General Taxonomy. Psychological Bulletin, 130, 19-65. http://dx.doi.org/10.1037/0033-2909.130.1.19

Joiner, G. W., \& Kashubeck, S. (1996). Acculturation, Body Image, Self-Esteem and Eating Disorder Symptomatology in Adolescent Mexican American Women. Psychology of Women Quarterly, 20, 419-435. http://dx.doi.org/10.1111/j.1471-6402.1996.tb00309.x

Kawamura, K. Y., Hunt, S. L., Frost, R. O., \& DiBartolo, P. M. (2001). Perfectionism, Anxiety, and Depression: Are the Relationships Independent? Cognitive Therapy and Research, 25, 291-301. http://dx.doi.org/10.1023/A:1010736529013

Kawash, G. F. (1982). A Structural Analysis of Self-Esteem from Pre-Adolescence through Young Adulthood: Anxiety and Extraversion as Agents in the Development of Self-Esteem. Journal of Clinical Psychology, 38, 301-311. http://dx.doi.org/10.1002/1097-4679(198204)38:2<301::AID-JCLP2270380212>3.0.CO;2-9

Kernis, M. H., Brown, A. C., \& Brody, G. H. (2000). Fragile Self-Esteem in Children and Its Associations with Perceived Patterns of Parent-Child Communication. Journal of Personality, 68, 225-252. http://dx.doi.org/10.1111/1467-6494.00096

Kong, F., \& You, X. (2013). Loneliness and Self-Esteem as Mediators between Social Support and Life Satisfaction in Late Adolescence. Social Indicators Research, 110, 271-279. http://dx.doi.org/10.1007/s11205-011-9930-6

Leary, M. R. (1990). Responses to Social Exclusion: Social Anxiety, Jealousy, Loneliness, Depression and Low Self-Esteem. Journal of Social and Clinical Psychology, 9, 221-229. http://dx.doi.org/10.1521/jscp.1990.9.2.221

Luo, J., Forbush, K. T., Williamson, J. A., Markon, K. E., \& Pollack, L. O. (2013). How Specific Are the Relationships between Eating Disorder Behaviors and Perfectionism? Eating Beha- 
viors, 14, 291-294. http://dx.doi.org/10.1016/j.eatbeh.2013.04.003

Lynd-Stevenson, R. M., \& Hearne, C. M. (1999). Perfectionism and Depressive Affect: The Pros and Cons of Being a Perfectionist. Personality and Individual Differences, 26, 549-562. http://dx.doi.org/10.1016/S0191-8869(98)00170-6

Lyubomirsky, S., \& Dickerhoof, R. (2006). Handbook of Girls and Women's Psychological Health. Oxford: Oxford University Press.

Mayhew, K. P., \& Lempers, J. D. (1998). The Relation among Financial Strain, Parenting, Parent Self-Esteem, and Adolescent Self-Esteem. The Journal of Early Adolescence, 18, 145-172. http://dx.doi.org/10.1177/0272431698018002002

McCranie, E. W., \& Bass, J. D. (1984). Childhood Family Antecedents of Dependency and Self-Criticism: Implications for Depression. Journal of Abnormal Psychology, 93, 3-8. http://dx.doi.org/10.1037/0021-843X.93.1.3

Mead, G. H. (1934). Mind, Self, and Society. Chicago, IL: University of Chicago Press.

Mitchelson, J. K., \& Burns, L. R. (1998). Career Mothers and Perfectionism: Stress at Work and at Home. Personality and Individual Differences, 25, 477-485.

http://www.researchgate.net/profile/Lawrence_Burns/publication/240174428_Career_mothers _and_perfectionism_stress_at_work_and_at_home/links/548db4d10cf2d1800d841dae.pdf http://dx.doi.org/10.1016/S0191-8869(98)00069-5

Özbay, Y., \& Misırlı-Taşdemir, Ö. (2003). Multidimensional Perfectionism Scale: Validity and Reliability Study, VII. Malatya: National Congress of Psychological Counseling and Guidance.

Pamir, Ç. O. (2008). The Relationship between High School Students' Perfectionism and Parenting Styles. Unpublished Master Thesis, Muğla: Muğla University.

Papps, B. P., \& O’Carroll, R. E. (1998). Extremes of Self-Esteem and Narcissism and the Experience and Expression of Anger and Aggression. Aggressive Behavior, 24, 421-438. http://dx.doi.org/10.1002/(SICI)1098-2337(1998)24:6<421::AID-AB3>3.0.CO;2-3

Park, N. (2004). The Role of Subjective Well-Being in Positive Youth Development. The Annals of the American Academy of Political and Social Science, 591, 25-39. http://dx.doi.org/10.1177/0002716203260078

Preacher, K. J., \& Hayes, A. F. (2008). Asymptotic and Resampling Strategies for Assessing and Comparing in Direct Effects in Multiple Mediator Models. Behavior Research Methods, 40, 879-891. http://dx.doi.org/10.3758/BRM.40.3.879

Preacher, K. J., Rucker, D., \& Hayes, A. F. (2007). Addressing Moderated Mediation Hypotheses: Theory, Methods, and Prescriptions. Multivariate Behavioral Research, 42, 185-227. http://dx.doi.org/10.1080/00273170701341316

Rice, K. G., Ashby, J. S., \& Slaney, R. B. (1998). Self-Esteem as a Mediator between Perfectionism and Depression: A Structural Equations Analysis. Journal of Counseling Psychology, 45, 304314. http://dx.doi.org/10.1037/0022-0167.45.3.304

Rogers, C. (1951). Client-Centered Therapy: Its Current Practice, Implications and Theory. London: Constable.

Rogers, C. (1959). A Theory of Therapy, Personality, and Interpersonal Relationships as Developed in the Client-Centered Framework. Reprinted In H. Kirschenbaum, \& V. Henderson (Eds.), The Carl Rogers Reader. Boston: Houghton Mifflin.

Rosenberg, M. (1962). The Association between Self-Esteem and Anxiety. Journal of Psychiatric Research, 1, 135-152. http://dx.doi.org/10.1016/0022-3956(62)90004-3

Rosenberg, M. (1965). Society and the Adolescent Self-Image. Princeton, NJ: Princeton University Press. http://dx.doi.org/10.1515/9781400876136 
Rosenberg, M. (1979). Conceiving the Self. Malabar, FL: Robert E. Krieger.

Roth, G., \& Assor, A. (2003). Autonomy Supporting and Suppressing Parental Practices as Predictors of Integrated, Rigid and Dis-Regulated Modes of Emotion Regulation in Children. Tampa, FL: SRCD.

Roth, G., Assor, A., Niemiec, C. P., Ryan, R. M., \& Deci, E. L. (2009). The Emotional and Academic Consequences of Parental Conditional Regard: Comparing Conditional Positive Regard, Conditional Negative Regard, and Autonomy Support as Parenting Practices. Developmental Psychology, 45, 1119-1142. http://dx.doi.org/10.1037/a0015272

Ryan, R. M., \& Deci, E. L. (2000). Self-Determination Theory and the Facilitation of the Intrinsic Motivation, Social Development and Well-Being. American Psychologist, 55, 68-78. http://dx.doi.org/10.1037/0003-066X.55.1.68

Sarıcam, H., Gençdoğan, B., \& Erzökan, A. (2012). The Examination of the Relationship between the University Students' Rejection Sensivities, Self-Esteem and Loneliness Levels. ProcediaSocial and Behavioral Sciences, 46, 2716-2720. http://dx.doi.org/10.1016/j.sbspro.2012.05.553

Saygın, Y., \& Arslan, C. (2009). An Investigation Social Support, Self-Esteem and Subjective Well-Being Level of College Students. Journal of Ahmet Keleşoğlu Education Faculty, 28, 207222.

Shafran, R., \& Mansell, W. (2001). Perfectionism and Psychopathology: A Review of Research and Treatment. Clinical Psychology Review, 21, 879-906. http://dx.doi.org/10.1016/S0272-7358(00)00072-6

Shavit-Miller, A., \& Assor, A. (2003). The Experience of Conditional Parental Regard and Its Effects on Development: A Study of Gender Differences. Padua: EARLI.

Sherry, S. B., Richards, J. E., Sherry, D. L., \& Stewart, S. H. (2014). Self-Critical Perfectionism Is a Vulnerability Factor for Depression but Not Anxiety: A 12-Month, 3-Wave Longitudinal Study. Journal of Research in Personality, 52, 1-5. http://dx.doi.org/10.1016/j.jrp.2014.05.004

Shim, S. S., Wang, C., \& Cassady, J. C. (2013). Emotional Well-Being: The Role of Social Achievement Goals and Self-Esteem. Personality and Individual Differences, 55, 840-845. http://dx.doi.org/10.1016/j.paid.2013.07.004

Slaney, R. B., \& Ashby, J. S. (1996). Perfectionists: Study of a Criterion Group. Journal of Counseling and Development, 74, 393-398. http://dx.doi.org/10.1002/j.1556-6676.1996.tb01885.x

Soenens, B., \& Vansteenkiste, M. (2010). A Theoretical Upgrade of the Concept of Parental Psychological Control: Proposing New Insights on the Basis of Self-Determination Theory. Developmental Review, 30, 74-99. http://dx.doi.org/10.1016/j.dr.2009.11.001

Sowislo, J. F., \& Orth, U. (2013). Does Low Self-Esteem Predict Depression and Anxiety? A Meta-Analysis of Longitudinal Studies. Psychological Bulletin, 139, 213-240. http://dx.doi.org/10.1037/a0028931

Stice, E. (2002). Risk and Maintenance Factors for Eating Pathology: A Meta-Analytic Review. Psychological Bulletin, 128, 825-848. http://dx.doi.org/10.1037/0033-2909.128.5.825

Stoeber, J., \& Otto, K. (2006). Positive Conceptions of Perfectionism: Approaches, Evidence, Challenges. Personality and Social Psychology Review, 10, 295-319. http://dx.doi.org/10.1207/s15327957pspr1004_2

Stoeber, J., \& Rambow, A. (2007). Perfectionism in Adolescent School Students: Relations with Motivation, Achievement, and Well-Being. Personality and Individual Differences, 42, 13791389. http://dx.doi.org/10.1016/j.paid.2006.10.015

Stoeber, J., Sherry, S. B., \& Nealis, L. J. (2015). Multidimensional Perfectionism and Narcissism: Grandiose or Vulnerable? Personality and Individual Differences, 80, 85-90. 
http://dx.doi.org/10.1016/j.paid.2015.02.027

Taşgit, M. S. (2012). Self-Esteem and Decision Making Styles of University Students. Unpublished Master Thesis, Karaman: University of Karamanoğlu Mehmet Bey.

Teng, Z., Liu, Y., \& Guo, C. (2015). A Meta-Analysis of the Relationship between Self-Esteem and Aggression among Chinese Students. Aggression and Violent Behavior, 21, 45-54. http://dx.doi.org/10.1016/j.avb.2015.01.005

Trzesniewski, K. H., Donnellan, M. B., Moffitt, T. E., Robins, R. W., Poulton, R., \& Caspi, A. (2006). Low Self-Esteem during Adolescence Predicts Poor Health, Criminal Behavior, and Limited Economic Prospects during Adulthood. Developmental Psychology, 42, 381-390. http://dx.doi.org/10.1037/0012-1649.42.2.381

Waschull, S. B., \& Kernis, M. H. (1996). Level and Stability of Self-Esteem as Predictors of Children's Intrinsic Motivation and Reasons for Anger. Personality and Social Psychology Bulletin, 22, 4-13. http://dx.doi.org/10.1177/0146167296221001

Workman, M., \& Beer, J. (1989). Self-Esteem, Depression and Alcohol Dependency among High School Students. Psychological Reports, 65, 451-455. http://dx.doi.org/10.2466/pr0.1989.65.2.451

Zhang, L., \& Leung, J. (2002). Moderating Effects of Gender and Age on the Relationship between Self-Esteem and Life Satisfaction in Mainland Chinese. International Journal of Psychology, 37, 83-91. http://dx.doi.org/10.1080/00207560143000252

Zhao, J., Kong, F., \& Wang, Y. (2012). Self-Esteem and Humor Style as Mediators of the Effects of Shyness on Loneliness among Chinese College Students. Personality and Individual Differences, 52, 686-690. http://dx.doi.org/10.1016/j.paid.2011.12.024

\section{Submit or recommend next manuscript to SCIRP and we will provide best service for you:}

Accepting pre-submission inquiries through Email, Facebook, LinkedIn, Twitter, etc.

A wide selection of journals (inclusive of 9 subjects, more than 200 journals)

Providing 24-hour high-quality service

User-friendly online submission system

Fair and swift peer-review system

Efficient typesetting and proofreading procedure

Display of the result of downloads and visits, as well as the number of cited articles

Maximum dissemination of your research work

Submit your manuscript at: http://papersubmission.scirp.org/ 